\title{
Active Control of Wing Flutter Using Piezoactuated Surface
}

\author{
S. Raja* and A. R. Upadhya ${ }^{\dagger}$ \\ National Aerospace Laboratories, Bangalore 560017, India \\ DOI: $10.2514 / 1.21660$
}

\begin{abstract}
A flutter suppression concept is demonstrated by performing wind-tunnel tests in a low subsonic flow regime. The wing model, with a trailing edge control surface, is constructed to have a bending-torsion flutter. The control surface is actuated by a flexure-hinged lead zirconate titanate stack mechanism acting as an aerodynamic effector. The flutter experiments are conducted using a digital controller, implemented in dSPACE DS1104, keeping the wing model at $4 \mathrm{deg}$ angle of attack. The wing response is measured by lead zirconate titanate sensors, which are used to generate the feedback control to vibrate the control surface in antiphase motion with respect to the main surface to introduce active aerodynamic control. It is noticed that both bending and torsion modes are stabilized in closed-loop configurations. The damping trend of the flutter mode shows an expanded flutter envelope that is estimated to be around $20 \%$. The actuators are operated within $1000 \mathrm{~V} / \mathrm{mm}$, though their allowable field strength is $1500 \mathrm{~V} / \mathrm{mm}$.
\end{abstract}

\section{Nomenclature}

$A_{0}$

$=$ equi

$=$

$=$

$=$

$=$

$=$

$=$

$=$

$=$

$=$

Subscript

$=$ amplifier

$=$ actuator

$=$ controller

$=$ disturbance

$=$ sensor

Received 8 December 2005; revision received 3 March 2006; accepted for publication 21 April 2006. Copyright (C) 2006 by the American Institute of Aeronautics and Astronautics, Inc. All rights reserved. Copies of this paper may be made for personal or internal use, on condition that the copier pay the $\$ 10.00$ per-copy fee to the Copyright Clearance Center, Inc., 222 Rosewood Drive, Danvers, MA 01923; include the code \$10.00 in correspondence with the CCC.

*Scientist, Aeroelasticity and Smart Structures Group, Structures Division; raja@css.cmmacs.ernet.in. Corresponding author.

†irector; director@css.nal.res.in.

\section{Introduction}

$\mathbf{T}$ HIN walled aircraft structures may develop divergent oscillations under the influence of unsteady aerodynamic forces, which affect the performance, stability, and safety of an aircraft. A typical case is the catastrophic-natured flutter that occurs due to the interaction between aerodynamic, elastic, and inertial forces. The flutter speed of an aircraft needs to be 1.2 times the diving speed to have a proper safety margin (FAR 25.629). This poses stringent constraints on the aerospace structural designers in terms of meeting the strength and stiffness requirements. Because lightweight composite materials are now extensively employed in aerospace structural construction, the structural vibrations induced by the aerodynamic forces take a long time to get damped out; they may even couple with the aerodynamic forces to develop dynamic instabilities.

An active control system (ACS) can be constructed with sensors, actuators, and a controller to bring down the vibration level of the elastic modes by changing the deformation shape, modifying the stiffness, and introducing damping into the vibrating system. Using ACS, the undesirable effects due to the external disturbances can be minimized to increase fatigue life and enhance the flutter margin to ensure the safety of the aircraft structural system. However, ACS implementation demands a large number of actuators and sensors, distributed over the entire structural domain. The use of conventional actuators (hydraulic/electrohydraulic) for structural control applications has limitations and also poses problems of structural integrity. In this context, the smart structure concept brings in a novel idea of integrating the multifunctional active materials into a structural system to provide built-in actuation, sensing, and control capabilities.

Piezoelectric materials are popularly employed for such structural control applications due to their fast electromechanical response, wider frequency band, etc. In addition, they can also generate a relatively large force and a reasonable displacement, if fabricated in an amplifiable device form. An attempt is made here to develop a new amplifiable actuating mechanism and subsequently use it for active flutter control.

Efforts have been made in the last three decades to design active flutter suppression systems, following classical control concepts such as the root-locus approach [1-3] and the frequency response method [4], besides optimal control theory [5]. Techniques such as Nissim's aerodynamic energy concept [6] and the method of fictitious structural modifications [7] have also been applied to solve the flutter control problem of lifting surfaces. Many investigators have also used optimal regulator theory for the design of the active flutter suppression systems [8-12].

In recent years, the dynamically efficient piezoelectric actuators have been widely used for structural control applications, in particular, for active vibration and aeroelastic controls. The 
piezoelectric actuators, in segmented form (patches), are employed in the feedback loops with an optimal control ideology (LQR), where a $49 \%$ flutter velocity enhancement is reported on a composite wing [13]. Wind-tunnel tests are conducted on a 2-degree-of-freedom wing model, surface bonded with lead zirconate titanate (PZT) patch actuators, to demonstrate the flutter suppression concept using the feedback control scheme [14]. Another interesting work reported on supersonic panel flutter control uses self-sensing and actuating piezoelectric patches, where the actuators and sensors are employed in a collocated configuration with output feedback control [15].

A review article has recently appeared to further emphasize the use of smart materials as actuators for aeroelastic and vibration controls [16]. The application of smart actuators (patches, active fiber composites, and multilayered stacks) to fixed wing aircraft and rotary wing configurations has been further discussed. Solutions through smart structure concepts to aeroelastic problems such as flutter and buffeting are critically examined. The store induced wing flutter is considered as a significant dynamic instability problem especially for fighter aircraft. One such problem is solved using an active pylon concept, employing $H_{\infty}$ control and piezoelectric actuator [17]. Of late, modal based state-space equations for aeroservoelastic design and analysis have been extended to incorporate piezoelectric strain actuators using the fictitious mass method [18].

The piezoelectric actuators have limitations in terms of induced strain, brittleness, high voltage requirements, etc. However, they are better suited for dynamic control applications due to their wide frequency band and fast responsive nature. It is also possible to use these actuators in proper device form, i.e., with a mechanical amplifier, to develop solutions for the real time structural control problems. The purpose of the research presented in this paper is to employ an active aerodynamic effector as a flutter suppression system in the subsonic flow regime. The combination of active control and smart structures is the basis for developing an active trailing edge control surface (effector), actuated by a new flexurehinged amplifiable actuator mechanism. The effector will be actuated to vibrate in the control bandwidth (covering flutter frequency) such that the aerodynamics of the control surface work against the aerodynamics of the main surface to achieve the required active aerodynamic control. For this purpose, a low-speed composite generic wing model is designed to have the bending-torsion flutter instability. Two multilayered stack actuators are used in the development of the flexure-hinged amplifiable actuating mechanism. The aerodynamic effector (active control surface) is built and integrated with the flexure-hinged amplifiable actuating mechanism. However, the feedback sensors (PZT patches) are placed on the wing surface to facilitate an antiphase motion of the control surface. Openand closed-loop wind-tunnel tests are successfully carried out to demonstrate the workability of the developed flutter suppression concept. The electromechanically actuated control surface can be employed not only in a wing for flutter control application, but also in a vertical fin as an auxiliary rudder for buffet load alleviation [19].

\section{Development of a New Amplifiable Actuating Mechanism}

The PZT stack is a multilayered actuator configuration that deforms along the longitudinal direction with a limited amount of stroke length ( $d_{33}$ actuation mode) when subjected to an electric field. The deformation may be partially or fully constrained to generate a force, which can be used for active vibration and flutter control applications. As mentioned earlier, two stack actuators are considered (PSt/150/5/40 VS10 APC®) to design an amplifiable actuating mechanism. The actuator data is presented in Table 1.

The stack actuators are positioned symmetrically at an angle such that they collectively produce a transverse resulting force. The schematic view of stack actuating mechanism is shown in Fig. 1. This mechanism has a rear block that has two symmetric semicylindrical grooves in the front and two tapped holes at the back. One end of the piezoelectric actuator is attached to the cylindrical cap, whereas the other end is joined to an end block. Further, the caps and the grooves in the rear block are designed to function as a journal bearing. The
Table 1 Actuator data (PSt/150/5/40 VS10 APC)

\begin{tabular}{lcc}
\hline \hline Description & Unit & Data \\
\hline Active height & $\mathrm{mm}$ & 46 \\
Layer thickness & $\mu \mathrm{m}$ & 100 \\
Diameter & $\mathrm{mm}$ & 10 \\
Stiffness & $\mathrm{N} / \mu \mathrm{m}$ & 12 \\
Young's modulus & $\mathrm{GPa}$ & 24.2 \\
Poisson's ratio & $\mathrm{m} / \mathrm{V}$ & 0.31 \\
Piezoelectric constant $\left(d_{33}\right)$ & $\mathrm{F} / \mathrm{m}$ & $374 \times 10^{-12}$ \\
Dielectric constant $\left(\kappa_{33}\right)$ & $\mathrm{V}$ & $1.531 \times 10^{-8}$ \\
Voltage range & $\mu \mathrm{m}$ & $-30 \ldots 150$ \\
Free deflection & $\mathrm{N}$ & $55 / 40$ \\
Blocking force & $\mathrm{KHz}$ & $800 / 150$ \\
Frequency band & & $<20$ \\
\hline \hline
\end{tabular}

entire mechanism can be integrated into the host structure by means of the tapped holes present in the rear block. The center arms help maintain the equilibrium position of the piezoelectric actuators by means of the applied prestress using a bolt. A parabolic groove (single axis flexure hinge, Fig. 2) is provided in each arm to develop a compliant mechanism so as to convert an axial motion of the actuators into an amplified transverse motion. These arms are the critical members in the entire mechanism because they have to hold the actuators in place, besides functioning as the flexural hinges. Among the two piezoelectric actuators, one is made to expand and the other to contract by applying input voltages with appropriate polarities. For a given dynamic equilibrium condition, the horizontal components cancel each other, and the vertical components together produce the transverse force and the required displacement. Furthermore, the resultant vertical force will produce a moment in the arm with respect to the flexural hinge.

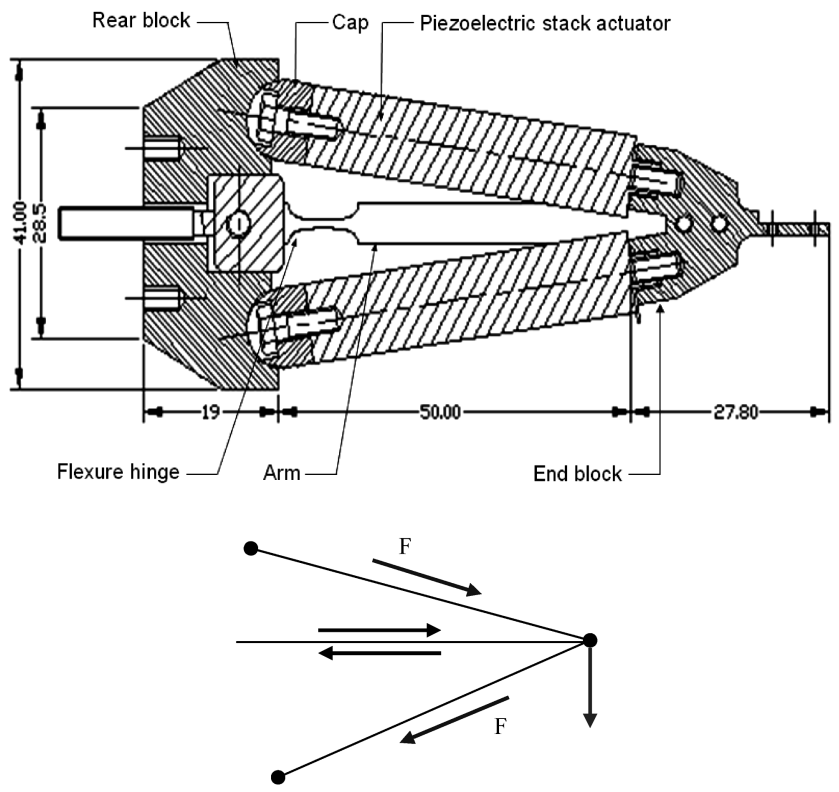

Fig. 1 Flexure-hinged stack actuating mechanism.
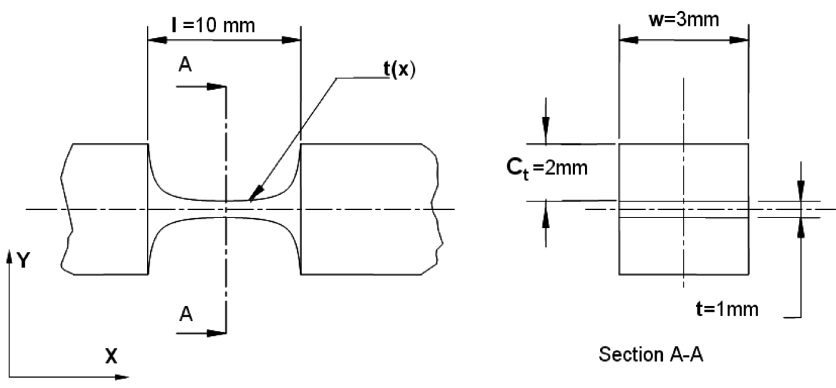

Section A-A

Fig. 2 Parabolic flexure-hinge. 


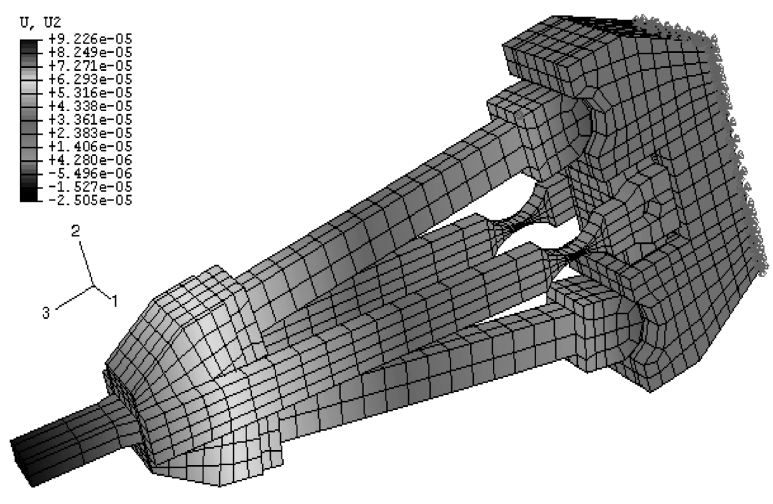

a) Transverse dispalcement in meter (Applied field $750 \mathrm{v} / \mathrm{mm}$ )

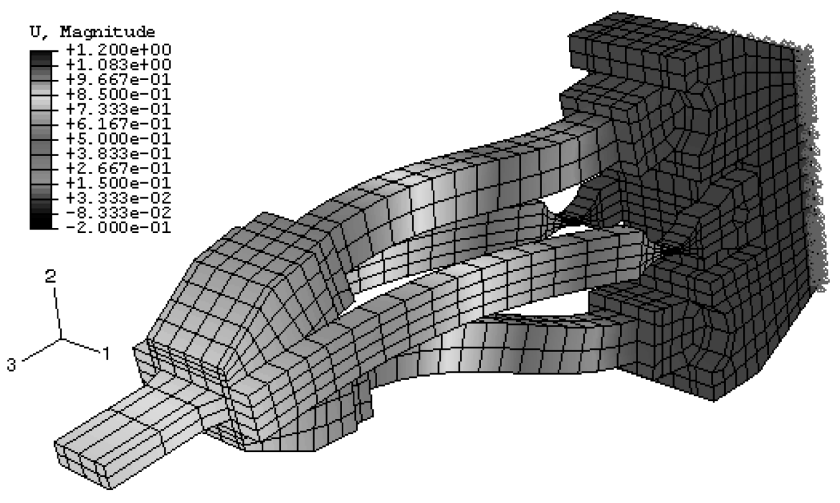

b) Normalized eigen vector of first elastic mode (Clamped-free)

Fig. 3 Finite element analysis on the flexure-hinged stack actuating mechanism.

A flexure-hinge based piezoelectric actuating mechanism is considered as a viable system for the flutter control application. The flexure hinges offer interesting benefits, and their merits and drawbacks are extensively reported [20,21]. A flexure-hinge based displacement amplifier is expected to produce an amplified displacement besides retaining a significant amount of force output. The generation of a large displacement output may develop a hightensile stress in the hinge, which is of great concern in the entire design process. Therefore, the maximum stress should be considered in terms of the fatigue strength of the material. Steel, aluminum, and titanium have been used as arm material, and a fatigue safety analysis is performed. Based on the analysis results, steel has been chosen for making the flexure arm.

A 3-D geometric model of the stack mechanism is designed and developed using AutoCAD2000, and this is exported to Hyper Mesh (Version 6) to build the required finite element model. Using the general purpose software ABAQUS® (C3D8 and C3D8E elements), a static piezoelectric analysis is carried out on the designed mechanism (refer to Fig. 3a). A friction-free contact is simulated using the contact analysis capability of ABAQUS. The free deflection versus the blocking force is estimated for various applied voltages. Further, the influence of flexure-hinge width on stress, blocking force, and free deflection of the mechanism is parametrically evaluated (refer to Fig. 4). The free-vibration analysis is performed on the stack amplification mechanism with a clampedfree condition to evaluate the natural frequencies of the assembled system of which the first elastic mode is the longitudinal vibration (1407.8 Hz; Fig. 3b). The concern here is to identify the fundamental mode because the stack mechanism will be operated in that mode. The dynamic interaction is another issue to be addressed normally while integrating the subsystems.

The flexure-hinged arms, rear block, end piece, and spacers are fabricated using a computer numerical control machine with a tolerance of less than $10 \mu \mathrm{m}$. The fabricated components are then anodized before assembling the mechanism. Using these components and two stack actuators, the designed mechanism is realized (see Fig. 5). The weight of the fabricated mechanism is around $88 \mathrm{~g}$ and it is very compact. Further, the functionality test is conducted on the mechanism by actuating the stacks in opposite phases. It is observed that the mechanism generates a transverse force $(\approx 50 \mathrm{~N}$ for $750 \mathrm{~V} / \mathrm{mm}$ ) that helps to vibrate the control surface in the desired way (see Fig. 5).

\section{Design, Analysis, and Ground Testing of the Low-Speed Flutter Model}

The aeroelastic research wing model with a trailing edge control surface is designed, which has a bending-torsion flutter mode (refer to Fig. 6a). To conduct the flutter study, a continuous and variable speed open-circuit wind tunnel is chosen [the $1.5 \times 1.5 \mathrm{~m}$ tunnel at National Aerospace Laboratories (NAL), Bangalore, India]. Since the maximum speed of this wind tunnel is $50 \mathrm{~m} / \mathrm{s}$, the wing model design is optimized to have instability around this velocity. The rectangular wing model is built with a glass fibre reinforced plastic (GFRP) variable thickness composite core plate $(300 \times 400 \mathrm{~mm})$ on which the PZT sensors (Table 2) are bonded. An accelerometer is mounted at the wing tip to measure its aeroelastic response, both in open- and closed-loop conditions (refer to Fig. 7). The core plate is further stiffened with an aluminum spar $(200 \times 15 \times 0.5 \mathrm{~mm})$ from its root to provide the required elastic constraint for the stack actuating mechanism.

The control surface has a $298 \mathrm{~mm}$ span and a $98 \mathrm{~mm}$ chord (28\% wing chord). It is fabricated with a GFRP plate (ply thickness $=0.25 \mathrm{~mm}, 8$ layers) on which two balsa $(4 \mathrm{~mm}$ thick) and three foam ribs (4 mm thick) are integrated. Finally, a GFRP skin (2 layers) is built to achieve the aerodynamic shape. The control surface is hinged to the wing core plate as shown in Fig. 7. The fabricated and tested stack actuating mechanism is subsequently integrated into the wing core plate and a proper connection is made with the control surface to set an offset of $3.0 \mathrm{~mm}$ from the hinge line and $2.0 \mathrm{~mm}$ above the plane of the hinge line. The offset provides the required stiffness for the control surface rotation. This geometric arrangement helps separate the control surface mode from the torsion mode of the wing model. However, the control surface mode is tuned
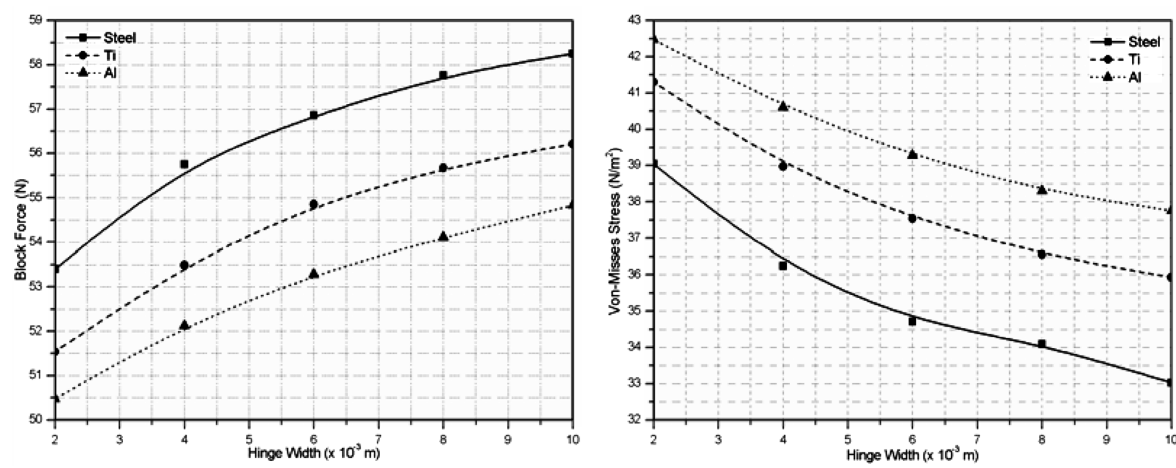

Fig. 4 Static characteristics of the mechanism for various flexural arm materials (applied field $750 \mathrm{~V} / \mathrm{mm}$ ). 


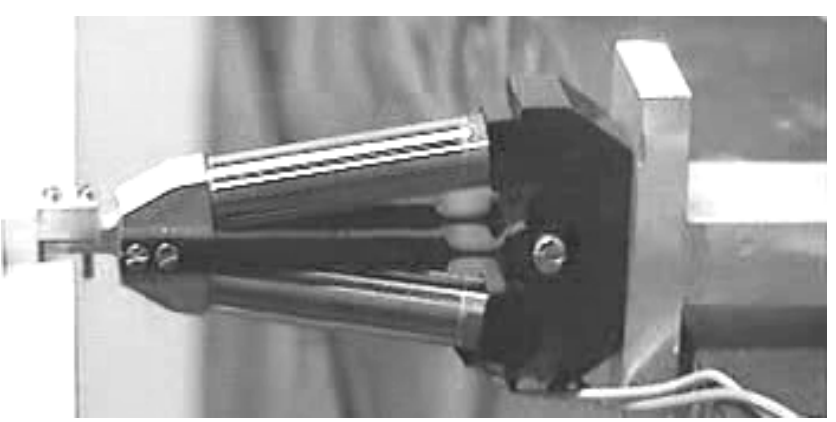

a) Fabricated mechanism

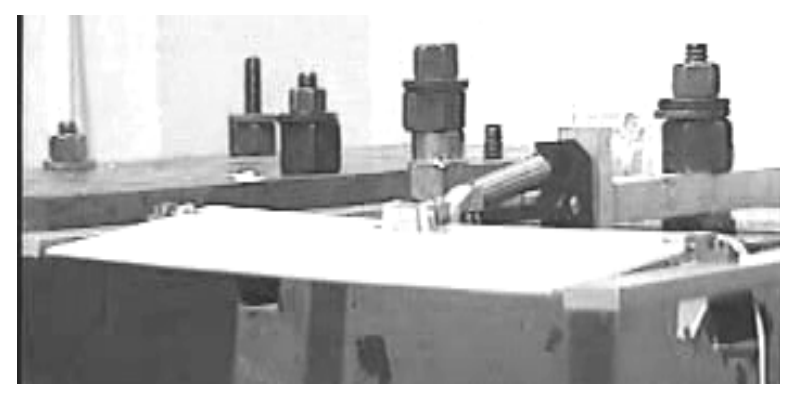

b) Control surface (GFRP, 300×100×2mm-plate ) deflection; hingedhinged configuration; tip deflection: $487 \mu \mathrm{m}$, applied field $750 \mathrm{v} / \mathrm{mm}$

Fig. 5 Functionality testing of the stack actuating mechanism.

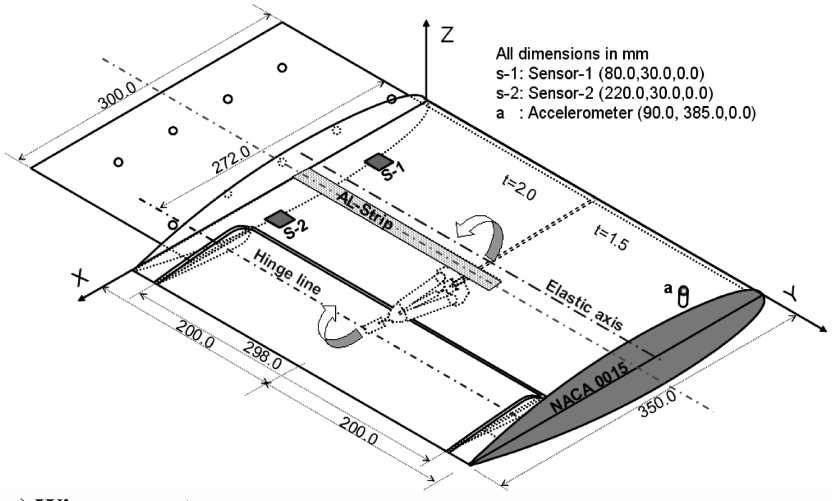

a) Wing geometry

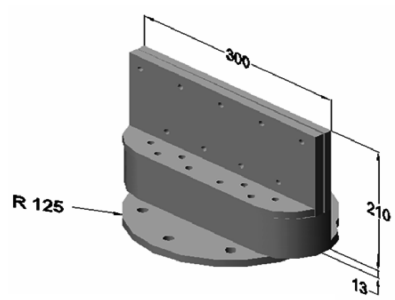

b) Wind tunnel wing mounting

Fig. 6 Low-speed flutter model.

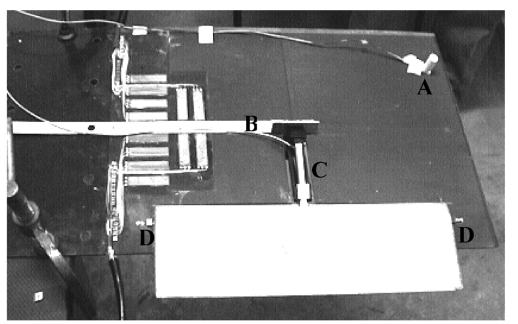

A - Accelerometer B - Aluminum spar C - Stack mechanism D - Hinge

Sensors are placed at the bottom

Fig. 7 Active plate with stack actuated control surface (top view).
Table 2 Sensor data (PZT-5H SPARKLER@, India)

\begin{tabular}{lcc}
\hline \hline Description & Unit & Data \\
\hline Size & $\mathrm{mm}$ & $15 \times 15$ \\
Thickness & $\mathrm{mm}$ & 0.5 \\
Young's modulus & $\mathrm{GPa}$ & 48.0 \\
Poisson's ratio & & 0.31 \\
Piezoelectric constant $\left(d_{31}\right)$ & $\mathrm{C} / \mathrm{m}^{2}$ & 13.15 \\
Dielectric constant $\left(\kappa_{33}\right)$ & $\mathrm{F} / \mathrm{m}$ & $3.01 \times 10^{-8}$ \\
Density & $\mathrm{kg} / \mathrm{m}^{3}$ & 7500 \\
\hline \hline
\end{tabular}

so that it develops a predominantly torsion effect on the main wing. A NACA 0015 aerofoil is built on the main surface using the segmented foam with a wall thickness of $4 \mathrm{~mm}$ as shown in Fig. $8(\approx 200 \mu \mathrm{m}$ tolerance is achieved on the wing surface).

The results of finite element analysis are compared with experiments at different stages to observe the change in system dynamics due to the addition of new components. The material data in Table 3 is used for the following components: 1) composite core plate, stack mechanism, and control surface; 2) wing model without control surface or stack mechanism; and 3) active aeroelastic wing model.

In the final assembled model, a $50 \mathrm{~g}$ lead mass is lumped on the control surface to bring down its rotational frequency. The frequency of control surface rotation is tuned so that it does not interfere with the bending-torsion flutter. Care is taken to keep this frequency close to the flutter frequency so that the vibration amplitude generated by electromechanical actuation is reasonable. Another $210 \mathrm{~g}$ lead mass is placed at the trailing edge of the wing surface to reduce the bending and torsion frequencies. These nonstructural masses are placed at appropriate locations (Table 4) on the wing model to have the flutter velocity close to the maximum tunnel velocity. The static analysis is performed to estimate the deflection of the model due to its selfweight (maximum of $5.29 \mathrm{~mm}$ ), and subsequently a coupled piezoelectric analysis is done using ABAQUS by actuating the stack mechanism with an electric field of $7.5 \times 10^{5} \mathrm{~V} / \mathrm{m}$ (control surface

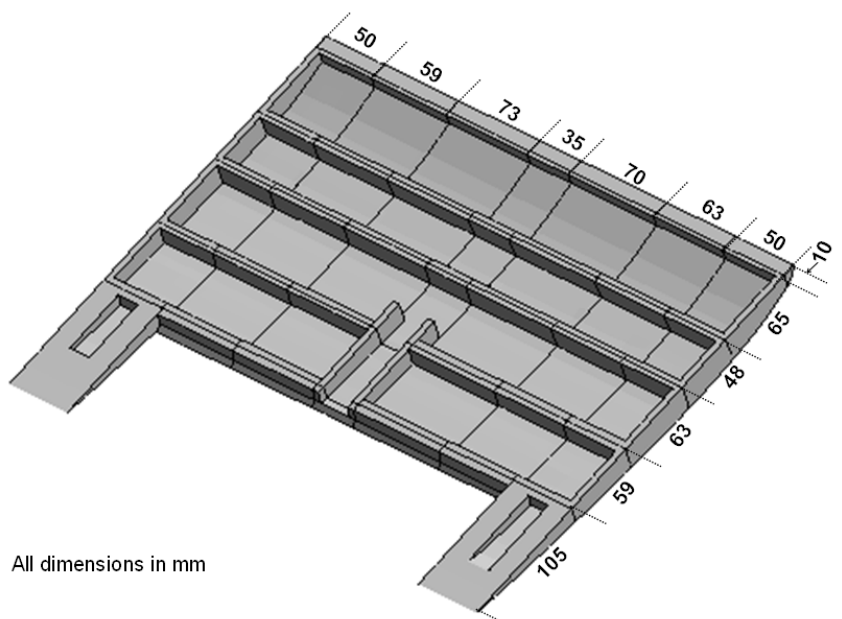

a) Aerodynamic surface using segmented foam pieces (bottom skin)

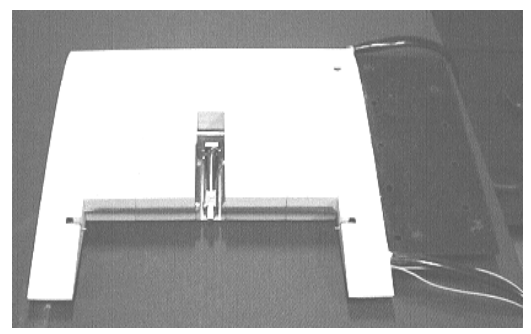

b) Fabricated wing model without control surface (top view)

Fig. 8 Wing model. 
Table 3 Material data

\begin{tabular}{lccc}
\hline \hline Description & Unit & GFRP & Foam \\
\hline Young's modulus & $\mathrm{GPa}$ & 20.0 & 0.07 \\
Poisson's ratio & & 0.15 & 0.38 \\
Density & $\mathrm{kg} / \mathrm{m}^{3}$ & 1830.0 & 90.0 \\
\hline \hline
\end{tabular}

Table 4 Nonstructural masses

\begin{tabular}{lcc}
\hline \hline Component & Location $[x, y, z], \mathrm{mm}$ & Mass, $\mathrm{g}$ \\
\hline Main surface & $(240.8,254.0,0.0)$ & 53.0 \\
& $(240.8,312.0,0.0)$ & 67.0 \\
Control surface & $(268.1,366.5,0.0)$ & 90.0 \\
& $(307.4,163.7,0.0)$ & 25.0 \\
& $(307.4,236.3,0.0)$ & 25.0 \\
\hline \hline
\end{tabular}

Table 5 Natural frequencies of active aeroelastic wing model

\begin{tabular}{lcccc}
\hline \hline \multirow{2}{*}{ Mode order } & \multicolumn{2}{c}{ Frequency, $\mathrm{Hz}$} & & \\
\cline { 2 - 3 } & FEM & Experiment & Damping (experiment) & Remarks \\
\hline 1 & 9.59 & 9.52 & 0.0243 & Bending \\
2 & 19.73 & 19.77 & 0.0166 & Torsion \\
3 & 28.47 & 27.32 & 0.032 & Control surface rotation \\
\hline \hline
\end{tabular}

tip displacement of $488 \mu \mathrm{m}$ ). The free-vibration analysis and the experimental results are presented for the wing model in Table 5 (see also Fig. 9).

\section{A. Open-Loop Flutter Analysis}

As the wing model is designed to flutter in the subsonic velocity profile, the doublet lattice method (DLM) of MSC/NASTRAN® is used to obtain the flutter characteristics. The flow is assumed to be inviscid, and the angle of attack is considered small so that the smalldisturbance potential flow approach may be applied to linearize the flow field. NASTRAN uses the DLM version where quadratic approximation is performed for integrating the kernel function. The line of doublets and control points are placed at the one-quarter chord and the three-quarter chord, respectively, along the centerline of each discrete element. Further, the lifting load is represented by the steady part (horseshoe vortex) and the oscillatory part (line of doublets).

The flutter analysis is carried out at different developmental stages of the wing model such as core plate, plate with control surface, and finally on the active aeroelastic wing model. The subsonic aerodynamic forces interact with the dynamics of the GFRP core plate to develop a bending-torsion flutter at $39.75 \mathrm{~m} / \mathrm{s}$. The flight conditions such as Mach 0.1 and sea level atmosphere $\left(1.226 \mathrm{Kg} / \mathrm{m}^{3}\right)$ have been considered in the analysis. Further, the aeroelastic analysis of the active wing model is performed using the aerodynamic mesh as shown in Fig. 10a. The zones represent the main surface and the aerodynamic effector, control surface. The final mesh size is obtained after conducting a convergence study. The flutter solution is obtained using the PK-method and is presented in the Fig. 10b and 10c. The analysis has shown that the flutter velocity is $50.34 \mathrm{~m} / \mathrm{s}$, which is very close to the test envelope. Besides it is observed that the third mode, i.e., control surface rotation, is stable and does not participate in the wing flutter.
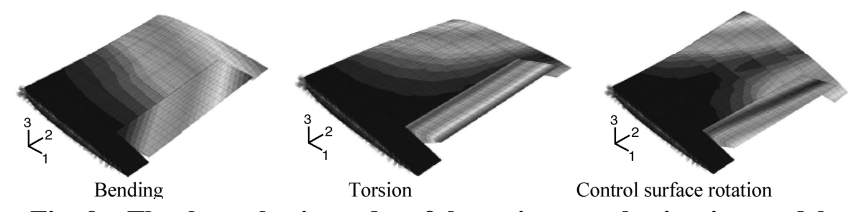

Fig. 9 The three elastic modes of the active aeroelastic wing model.

\section{B. Static Aeroelastic Analysis on the Wing Model}

The static aeroelastic analysis is performed to estimate the steady loads acting over the wing model. Using the analysis capabilities of MSC/NASTRAN, the steady aerodynamic loads are obtained for an angle of attack of $4 \mathrm{deg}$ of the main surface and $2 \mathrm{deg}$ of the control surface. The loads are estimated for a velocity of $40 \mathrm{~m} / \mathrm{s}$ at sea level conditions $(34 \mathrm{~N})$. The force and moment distributions on the designed wing model are presented in Fig. 11a and 11b. Further, a detailed stress analysis is performed by considering a safety factor of 1.5. The loads are applied on both the top and bottom surfaces of the wing model to compute the stresses to ensure its safety during windtunnel testing.

\section{Active Vibration Control Studies on the Active Aeroelastic Wing Model}

The main emphasis of the present research is to demonstrate the flutter speed enhancement scheme using the piezoactuated control surface. Therefore, the control surface is vibrated to act as an aerodynamic effector with the help of a stack actuating mechanism. Hence, the workability of this mechanism is studied experimentally under a wind-off condition, and its effectiveness in controlling the bending and torsion vibration is then evaluated [22]. A sine sweep disturbance (covering the control bandwidth of 8 to $20 \mathrm{~Hz}$ ) is applied through a shaker to the wing model (shaker location, $x=61.1 \mathrm{~mm}$, $y=28.8 \mathrm{~mm}$, vertically mounted). The closed-loop experiments are conducted with the help of a dSPACE DS1104 board, where the displacement feedback control is implemented. The control signal is generated using PZT sensors located on the main surface. The PZT sensor signal (charge) may be directly used in a closed-loop configuration, which is proportional to the strain developed (due to deformation). The feedback voltage is obtained by amplifying the sensor signal with a suitable gain. The experimental implementation of displacement and velocity feedback using PZT sensors has been broadly discussed [23].

\section{Open- and Closed-Loop Wind-Tunnel Studies}

The open-loop flutter analysis of the fabricated model has been updated, including the structural damping (measured). A state-space model is built for this purpose, and the equations are briefly presented. 


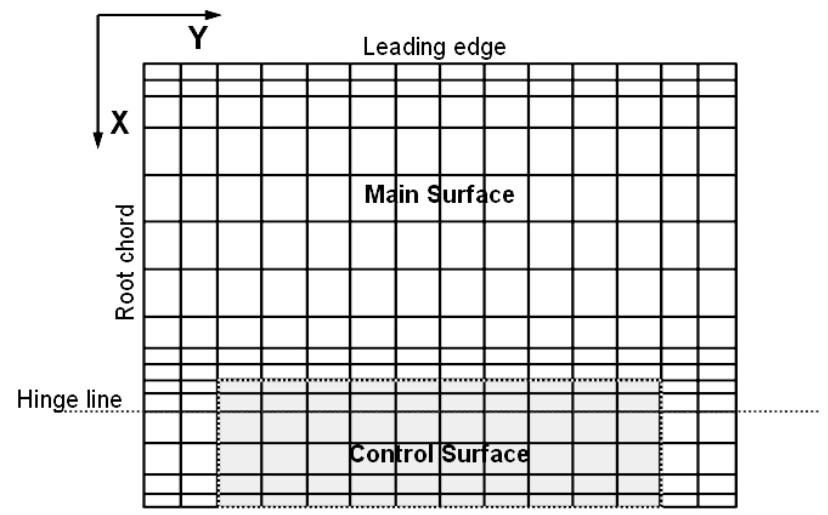

a) Aero mesh for DLM based flutter analysis
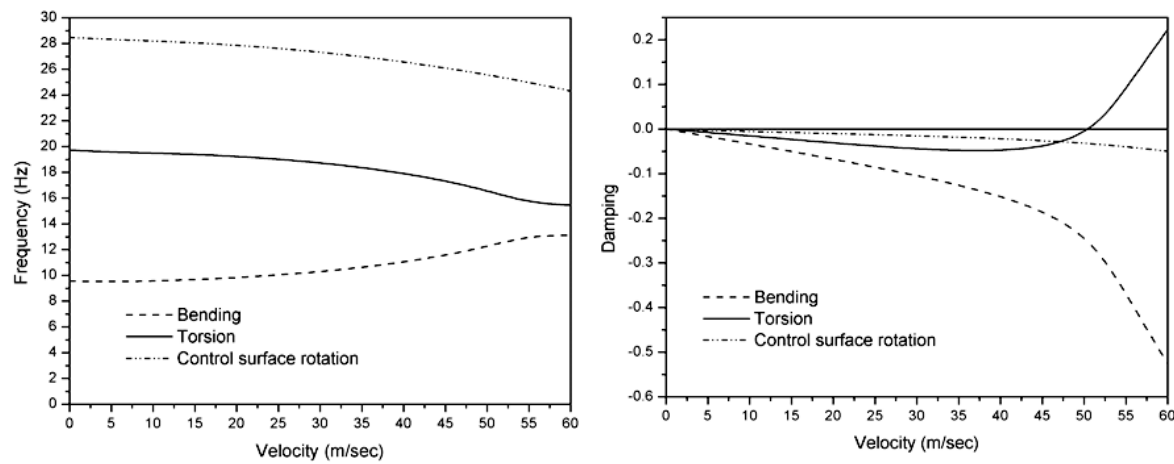

b) U-f plot

c) U-g plot

Fig. 10 Aeromodel and open-loop flutter characteristics of the active aeroelastic wing model.

The open-loop flutter solution in the " $s$ " domain is expressed as follows:

$$
\begin{gathered}
\left([\bar{M}] s^{2}+[\bar{D}] s+\frac{1}{2} \rho U^{2}[\bar{Q}(k)]+[\bar{K}]\right)\{q\}=0 \\
k=\frac{\omega b}{U}, \quad s=i \omega, \quad i k=\frac{s b}{U}
\end{gathered}
$$

where $\bar{M}=\psi^{T} M \psi, \bar{D}=\psi^{T} D \psi, \bar{K}=\psi^{T} K \psi$, and $\bar{Q}(k)=A_{0}+$ $A_{1}(i k)+A_{2}(i k)^{2}$ are the generalized aerodynamic coefficients obtained from NASTRAN.

The above second-order equation may be written as two first-order equations in the state variable form with structural damping using a new state vector $\{x\}=\left\{x_{1} x_{2}\right\}^{T}=\{q, \dot{q}\}^{T}$.

A complex eigenvalue problem is then formed and solved for a range of velocities.

$$
\left\{\begin{array}{l}
\dot{x}_{1} \\
\dot{x}_{2}
\end{array}\right\}=\left[\begin{array}{cc}
0 & I \\
-\left(\frac{[\bar{K}]+(1 / 2) \rho U^{2}\left[A_{0}\right]}{[\bar{M}]+(1 / 2) \rho b^{2}\left[A_{2}\right]}\right) & -\left(\frac{[\bar{D}]+(1 / 2) \rho U b\left[A_{1}\right]}{[\bar{M}]+(1 / 2) \rho b^{2}\left[A_{2}\right]}\right)
\end{array}\right]\left\{\begin{array}{l}
x_{1} \\
x_{2}
\end{array}\right\}
$$

The complex roots of Eq. (2) indicate the damping and frequency behavior of the active wing, using which the flutter velocity and frequency are estimated. The discrete air load coefficients are approximated as continuous function for flutter calculation using rational polynomials in the Laplace domain without considering aerodynamic lag terms [24]. The approximation coefficients $A_{0}, A_{1}$, and $A_{2}$ are obtained in the matrix form by the least-squares error technique. With the inclusion of structural damping, the open-loop flutter analysis shows that the flutter velocity is $52.56 \mathrm{~m} / \mathrm{s}$ and the flutter frequency is $16.17 \mathrm{~Hz}$.
The closed-loop system equation can then be built as follows:

$$
\begin{gathered}
\left([\bar{M}]+\frac{1}{2} \rho b^{2}\left[A_{2}\right]\right) \dot{x}_{2}+\left([\bar{D}]+\frac{1}{2} \rho U b\left[A_{1}\right]\right) x_{2} \\
+\left([\bar{K}]+\frac{1}{2} \rho U^{2}\left[A_{0}\right]\right) x_{1}=f_{a}+f_{d}
\end{gathered}
$$

where $f_{a}=-\bar{K}_{a} \cdot \phi_{a}, f_{d}=B_{d} \cdot u_{d}$.

The smart aeroelastic system in its final state variable form is obtained as

$$
\begin{aligned}
& \left\{\begin{array}{l}
\dot{x}_{1} \\
\dot{x}_{2}
\end{array}\right\}=\left[\begin{array}{cc}
0 & I \\
-\left(\frac{[\bar{K}]+(1 / 2) \rho U^{2}\left[A_{0}\right]}{[\bar{M}]+(1 / 2) \rho b^{2}\left[A_{2}\right]}\right) & -\left(\frac{[\bar{D}]+(1 / 2) \rho U b\left[A_{1}\right]}{[\bar{M}]+(1 / 2) \rho b^{2}\left[A_{2}\right]}\right)
\end{array}\right]\left\{\begin{array}{l}
x_{1} \\
x_{2}
\end{array}\right\}
\end{aligned}
$$

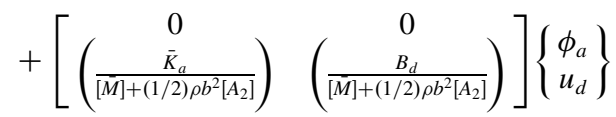

$$
\begin{aligned}
& \phi_{s}=\left[\begin{array}{ll}
\bar{K}_{s} & 0
\end{array}\right]\left\{\begin{array}{l}
x_{1} \\
x_{2}
\end{array}\right\} \\
& \phi_{a}=-G \phi_{s}
\end{aligned}
$$

The constant feedback gain $G$ is tuned by disturbing the wing model with a band limited white noise (located at $x=61.1 \mathrm{~mm}$, $y=28.8 \mathrm{~mm}$ ). The gains are presented as field strength in Table 6 .

By considering the safety of both the tunnel and the model, the wind-tunnel experiments have been limited up to a maximum speed of $40 \mathrm{~m} / \mathrm{s}$. The classical flutter procedure estimates the variation of the frequencies and damping values of the participating modes with respect to airspeed. The decreasing trend in the damping of an elastic mode or the modes indicates the nature of the instability of the vibrating aeroelastic system. The variation in the frequency and damping of participating modes can be obtained from the measured 


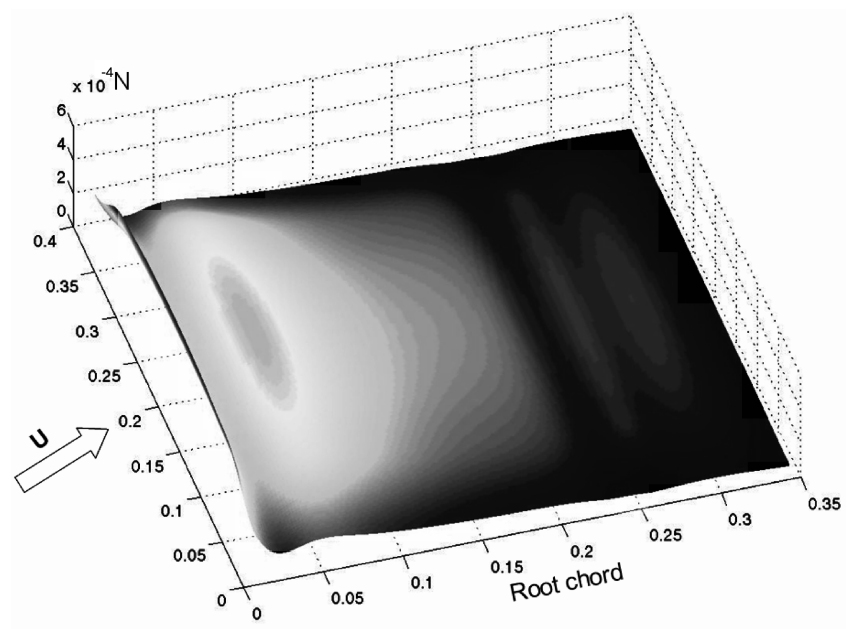

a) Force distribution

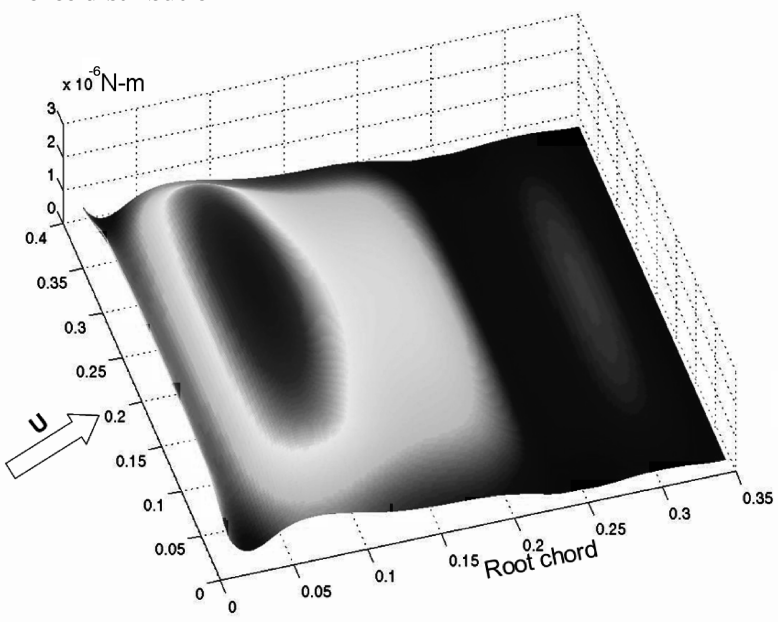

b) Moment distribution

Fig. 11 Static aeroelastic analysis on the aeroelastic wing model.

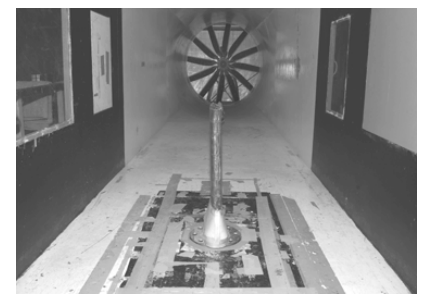

a) Front view

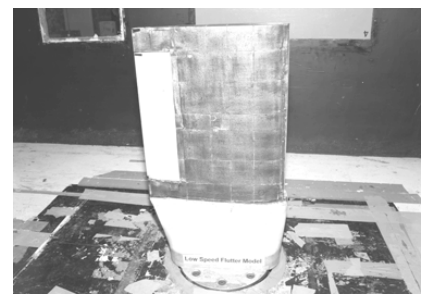

b) Side view
Fig. 12 Low-speed flutter model floor mounted in $1.5 \mathrm{~m}$ NAL wind tunnel.

structural response. The open-loop flutter experiments are carried out with a controller-off condition and, for the closed-loop flutter enhancement tests, the stack mechanism is actuated through a digital controller using the displacement feedback in the velocity range 10 to $40 \mathrm{~m} / \mathrm{s}$. As the tunnel testing is restricted to $40 \mathrm{~m} / \mathrm{s}$, and due to the fact that the estimated open-loop flutter velocity is around $52.56 \mathrm{~m} / \mathrm{s}$, a third-order polynomial curve fitting has been adopted for the available data $(10-40 \mathrm{~m} / \mathrm{s})$ to extrapolate the critical velocity.

\section{A. Floor Mounted Active Aeroelastic Wing Model}

The instrumented active aeroelastic wing model is floor mounted to avoid the gravity effect (refer to Fig. 12). The details of the supporting plate (mild steel) and the structural construction (foam \& GFRP) over it are presented in Fig. 6b. This type of fixture arrangement has ensured a clamped-free boundary effect for the wing
Table 6 Feedback gain (constant gain controller)

\begin{tabular}{lcc}
\hline \hline Velocity & Unit & Gain, $G_{A}$ \\
\hline $10-22 \mathrm{~m} / \mathrm{s}$ & $\mathrm{V} / \mathrm{mm}$ & 700 \\
$22-32 \mathrm{~m} / \mathrm{s}$ & $\mathrm{V} / \mathrm{mm}$ & 750 \\
$32-40 \mathrm{~m} / \mathrm{s}$ & $\mathrm{V} / \mathrm{mm}$ & 800 \\
\hline \hline
\end{tabular}

model (cantilever half-wing). The supporting part is also given a smooth aerodynamic shape with the NACA0015 configuration. The adopted instrumentation scheme for open- and closed-loop experiments involves the LMS $®$ based data acquisition system and the dSPACE DSP based feedback control system (Fig. 13). The connecting wires of the sensors and actuators are bunched together and taken through a slot (in the floor) and terminated at the junction box. To minimize the interference of electrical and tunnel noise, proper care has also been taken by selecting multicore shielded cables and covering the PZT sensors with a thin aluminum foil.

\section{B. Open- and Closed-Loop Experiments with a Stack Mechanism Actuated Control Surface}

The aerodynamic effector concept using an active control surface has been experimentally attempted. The PZT sensor signal (located on the main wing) is used to implement a proportional feedback control. The sensor signal (finite impulse response filtered) is first 180 deg phase shifted and then conditioned with the help of stack amplifier before applying it to the stack actuating mechanism (pushpull mode). It is very much essential to have a proper phase margin for the controller while operating it in a turbulent environment. Therefore, active phase compensation is required for real time application. The working principle of this actuating mechanism is presented in Sec. II. As the prime task is to evaluate the functionality of the proposed flutter control mechanism, only a simple control law is used. However, a logical adaptive control concept is essential to implement this mechanism for a real time application. The control system design has been vastly improved in recent years to account for model uncertainty, measurement and process noise, etc. Because a fixed gain controller is tried in the present case, it is possible that the system will become unstable due to adverse excitation frequencies outside the control bandwidth ( 8 to $20 \mathrm{~Hz}$ ). The closed-loop windtunnel tests are therefore conducted after analyzing the data of the open-loop tests in the velocity range 10 to $40 \mathrm{~m} / \mathrm{s}$. However, for practical applications, it is necessary to use a variable gain controller that will adjust its gain in real time with suitable phase compensation.

The stack actuators can be operated in the range of -200 to $1500 \mathrm{~V} / \mathrm{mm}$; however, the closed loop experiments are conducted by operating them with less than $1000 \mathrm{~V} / \mathrm{mm}$ using a digital controller (refer to the Simulink model in Fig. 14). The model is kept at an angle of attack of 4 deg during the tests. As mentioned earlier, the entire velocity spectrum $(10-40 \mathrm{~m} / \mathrm{s})$ has been split into three regimes, i.e., "safe" (10-22 m/s), "subcritical" (22-32 m/s), and

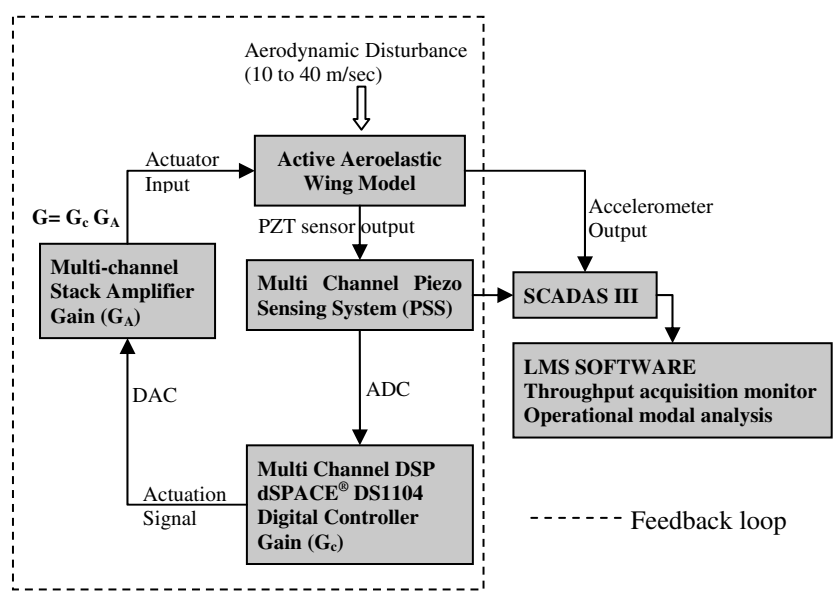

Fig. 13 Block diagram of active flutter control scheme. 


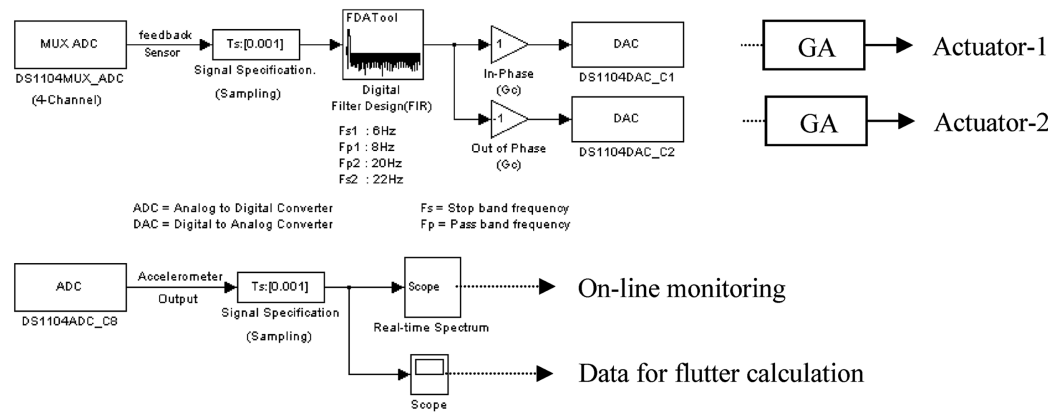

Fig. 14 Simulink model for actuating the control surface in a closed loop.

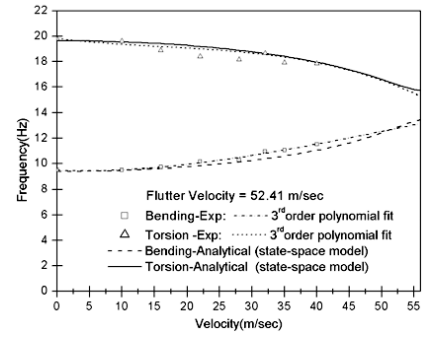

a) U-f plot

a) U-f plot ical).

"critical" (32-40 m/s), as a precautionary measure to ensure the tunnel and model safety. The aeroelastic response of the model is measured through an accelerometer and subsequently collected in the LMS SCADAS III system. In addition, the PZT sensor response is also collected.

\section{Flutter Speed Enhancement}

The processed results for both open- and closed-loop experiments are depicted in Figs. 15-18. The frequency and damping variation due to aerodynamic interaction can be clearly seen. Because it is a classical-type bending-torsion flutter, the torsion mode becomes unstable due to the interaction of the bending mode in the presence of unsteady aerodynamics, and its frequency decreases with increasing speed. The velocity versus damping $(V-g)$ plot interestingly shows that the damping of both the torsion and bending modes has been substantially enhanced with the help of the flutter control mechanism (aerodynamic effector). The aerodynamic effector helps modify the closed-loop flutter by introducing aerodynamic stiffness, aerodynamic damping, and aerodynamic inertia [Eq. (4)]. It is also evident from the observed trend that aerodynamic damping plays a crucial role in stabilizing the flutter mode.

Because of the limitation on the testing velocity $(<40 \mathrm{~m} / \mathrm{s})$, the closed-loop flutter characteristics of the research aeroelastic wing model beyond $40 \mathrm{~m} / \mathrm{s}$ have been extrapolated using a third-order polynomial curve fitting approach. This attempt has been made primarily to show that the flutter instability is shifted from the actual open-loop case using the smart structure based active control concept (Figs. 16 and 17). The $V-g$ plot clearly brings out the fact that the flutter may occur after $52.41 \mathrm{~m} / \mathrm{s}$, and the extrapolated damping trend predicts it at around $64.0 \mathrm{~m} / \mathrm{s}$. Nevertheless, this is a logical conclusion drawn from the evidence of damping trend that has been observed with the experiments until $40 \mathrm{~m} / \mathrm{s}$. In light of these findings, around $20 \%$ flutter speed enhancement is estimated with the

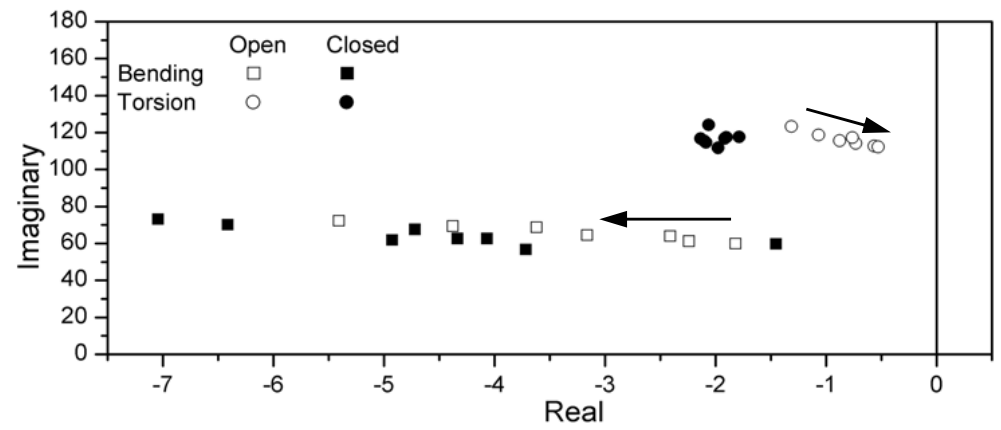

a) Root locus plot

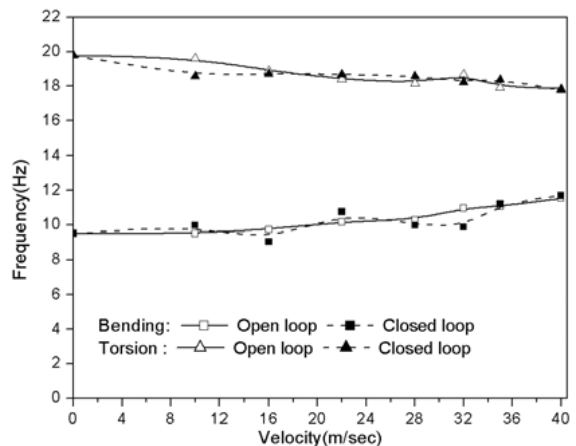

b) U-f plot

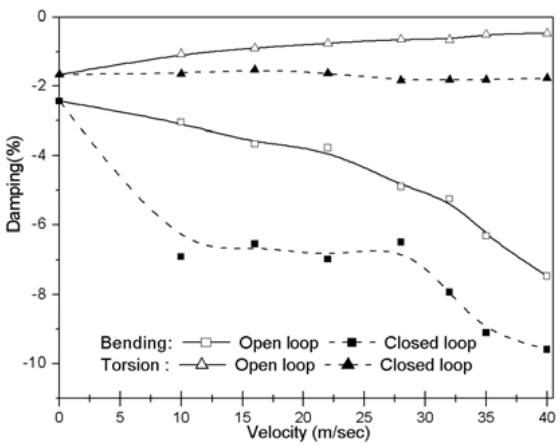

c) U-g plot

Fig. 16 Open- and closed-loop flutter characteristics (experimental). 


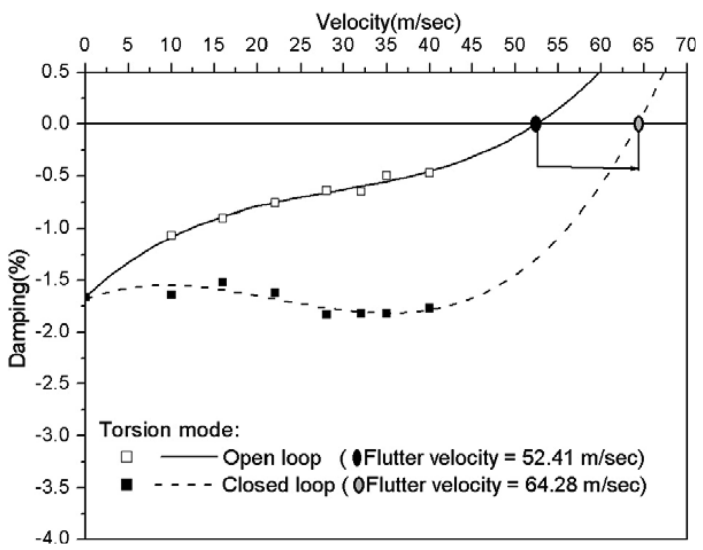

Fig. 17 Flutter velocity enhancement $(\approx 20 \%)$.

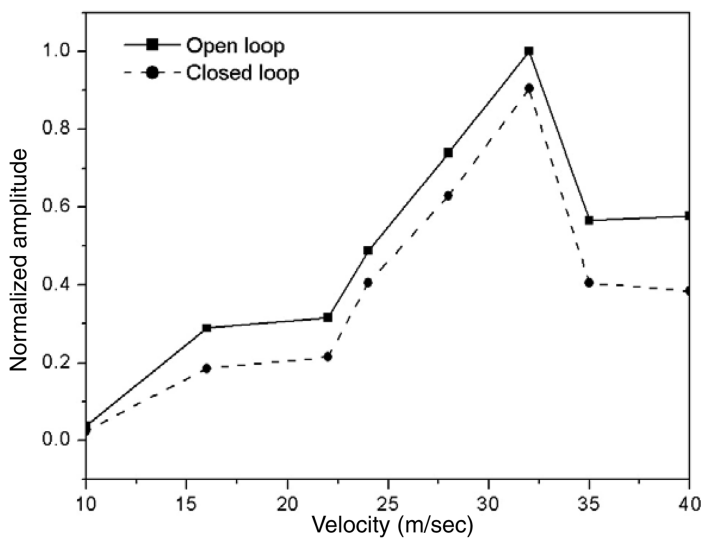

Fig. 18 Bending mode amplitude.

proposed active flutter control scheme, using the actuators up to their $60 \%$ potential (field strength $=800 \mathrm{~V} / \mathrm{mm}$ ). Finally, the observed bending mode amplitude trend substantiates that the flutter mode (torsion) will have relatively less interference from the bending mode in the closed-loop configuration (see Fig. 18). Based on the experimental results presented so far, a logical conclusion can be made that the use of control surface aerodynamics is efficient in controlling the flutter characteristics of the vibrating aeroelastic system. However, the study does not claim that the proposed control law is quite sufficient and that the concept will work in any velocity regime or frequency band, especially in turbulent atmospheric conditions (like the transonic region). Nevertheless, the active aerodynamic control concept is systematically approached and is experimentally demonstrated to address the complicated problem of wing flutter control.

\section{Conclusions}

The present study has experimentally shown the flutter speed enhancement on a composite wing model using an active aerodynamic control concept. The wing model is designed, constructed, and tested in a $1.5 \mathrm{~m}$ low-speed wind tunnel. A trailing edge control surface is actuated by a flexure-hinged stack amplification mechanism, which is employed as an aerodynamic effector. The control bandwidth takes into account the variation of the two elastic modes that participate in the flutter mechanism. It is observed that the bending and torsion modes are stabilized in the closed-loop configurations. Also, it is evident from the damping trend of these modes that the bending-torsion flutter boundary is shifted substantially. The closed-loop flutter tests are limited up to $40 \mathrm{~m} / \mathrm{s}$ because the tunnel is a suction based atmospheric-type tunnel, where the safety of tunnel blades depends on model safety.

\section{Acknowledgements}

We acknowledge the funding received to carry out this research program from Development Initiative for Smart Aircraft Structures (DISMAS), Aeronautical Development Agency, Bangalore, India. The authors appreciate the technical contribution of Shashikala Rajappa, S. Janardhanam, D. Sundararajan, and R. Sreedeep, Scientists, Aeroelasticity Group, Structures Division, National Aerospace Laboratories, India, for the successful completion of this program. The help received from S. Bhogle, head of the Information Management Division, while preparing the revised manuscript is sincerely appreciated.

\section{References}

[1] Horikawa, H., and Dowell, E. H., "An Elementary Explanation of the Flutter Mechanism with Active Feedback Controls," Journal of Aircraft, Vol. 16, No. 4, 1979, pp. 225-232.

[2] Hwang, C., Johnson, E. H., and Pi, W. S., "Recent Development of the YF-17 Active Flutter Suppression System," Journal of Aircraft, Vol. 18, No. 7, 1981, pp. 537-545.

[3] Waszak, M. R., and Srinathkumar, S., "Flutter Suppression for the Active Flexible Wing: A Classical Design," Journal of Aircraft, Vol. 32, No. 1, 1995, pp. 61-67.

[4] Peloubet, P. R., Jr., Haller, R. L., and Bolding, R. M., "F-16 Flutter Suppression System Investigation," AIAA Paper 80-0768, 1980.

[5] Mukhopadhyay, V., "Flutter Suppression Control Law Design and Testing for the Active Flexible Wing," Journal of Aircraft, Vol. 32, No. 1, 1995, pp. 45-51.

[6] Nissim, E., "Flutter Suppression Using Active Controls Based on the Concept of Aerodynamic Energy," NASA TN D-6199, 1971.

[7] Freymann, R., "New Simplified Ways to Understand the Interaction between Aircraft Structures and Active Control System," AIAA Guidance and Control Conference, CP-848, AIAA, New York, 1984, pp. 233-245; also AIAA Paper 1984-1868.

[8] Lyons, M. G., Vepa, R., McIntosh, S. C., Jr., and Debra, D. B., "Control Law Synthesis and Sensor Design for Active Flutter Suppression," AIAA Paper 73-832, 1973.

[9] Edwards, J. W., "Unsteady Aerodynamic Modelling and Active Aeroelastic Control," NASA CR-148019, 1977.

[10] Newsom, J. R., "Active Flutter Suppression Synthetic Using Optimal Control Theory," M.S. Thesis, George Washington Univ., Washington, D.C., 1978.

[11] Newsom, J. R., "A Method for Obtaining Practical FlutterSuppression Control Laws Using Results of Optimal Control Theory," NASA TP-1471, 1979.

[12] Mukhopadhyay, V., Newsom, J. R., and Abel, I., "Reduced-Order Optimal Feedback Control Law Synthesis for Flutter Suppression," Journal of Guidance, Control, and Dynamics, Vol. 5, No. 4, 1982, pp. 389-395.

[13] Nam, C., and Kim, Y., "Optimal Design of Composite Lifting Surface for Flutter Suppression with Piezoelectric Actuators," AIAA Journal, Vol. 33, No. 10, 1995, pp. 1897-1904.

[14] Heeg, J., "Analytical and Experimental Investigation of Flutter Suppression by Piezoelectric Actuation," NASA TP-3241, 1993.

[15] Döngi, F., Dinkler, D., and Kröplin, B., "Active Panel Flutter Suppression Using Self-Sensing Piezoactuators," AIAA Journal, Vol. 34, No. 6, 1996, pp. 1224-1230.

[16] Giurgiutiu, V., "Review of Smart-Materials Actuation Solutions for Aeroelastic and Vibration Control," Journal of Intelligent Material Systems and Structures, Vol. 11, July 2000, pp. 525-544.

[17] Gade, P. V. N., and Inman, D. J., "Two-Dimensional Active Wing/Store Flutter Suppression Using $H_{\infty}$ Theory," Journal of Guidance, Control, and Dynamics, Vol. 20, No. 5, 1997, pp. 949-955.

[18] Karpel, M., and Moulin, B., "Models for Aeroservoelastic Analysis with Smart Structures," Journal of Aircraft, Vol. 41, No. 2, 2004, pp. 314-321.

[19] Breitsamter, C., "Aerodynamic Active Control for Fin-Buffet Load Alleviation," Journal of Aircraft, Vol. 42, No. 5, 2005, pp. 1252 1263.

[20] Xu, W., and King, T., "Flexure Hinges for Piezoactuator Displacement Amplifiers: Flexibility, Accuracy, and Stress Considerations," Precision Engineering, Vol. 19, No. 1, 1996, pp. 4-10.

[21] Lobontiu, N., and Garcia, E., "Two-Axis Flexure Hinges with Axially-Collocated and Symmetric Notches," Computers and Structures, Vol. 81, No. 13, May 2003, pp. 1329-1341.

[22] Upadhya, A. R., and Raja, S., "Application of Smart Structural 
Concepts for Vibration and Aeroelastic Problems at NAL," International Conference on Computational and Experimental Engineering and Sciences Paper ICCES0520050816781, 2005.

[23] Raja, S., Sinha, P. K., and Prathap, G., "Active Stiffening and Active Damping Effects on Closed Loop Vibration Control of Composite
Beams and Plates," Journal of Reinforced Plastics and Composites, Vol. 22, No. 12, 2003, pp. 1101-1121.

[24] Barai, A., Raja, S., and Rajagopal, P., "Active Flutter Suppression of a Cantilevered Plate at Supersonic Speed," National Aeronautical Lab., Rept. NAL-TM-ST-9302, Bangalore, India, 1993. 